\title{
Marketing the library:
The library media fair
}

\author{
By Cheryl LaGuardia and Janet Martorana
}

\section{Getting the word out about library technology}

n recent years our library, like many others, has gone from being a technologically static organization to one that provides a wide array of online services. Our patrons now have access to online and ondisk research tools located both on our home systems and all over the world across the Internet. Unfortunately, comparatively few of our clients know what we offer.

Patrons still tend to come to libraries for traditional types of bibliographic information in traditional formats: books, journals, tapes, etc. They go elsewhere for the exciting, cutting-edge resources: to information brokers for "the newest update," to computer centers for computer-assisted instruction, to microcomputer labs for graphics and publishing resources, and to computerized writing centers for some of their most pressing and creative needs.

Libraries offer free access to much of the same information patrons have to pay for elsewhere. But since our regular clientele doesn't think of the library as being in the vanguard of computer developments, our computerized services have been under utilized. It is frustrating and wasteful to have both information and access, but not to have much of a clientele. More importantly, given the "downsizing" going on in libraries, higher use and demand for our computerized services would help us justify our very existence.

\section{What we haven't told them}

Given the amount of time and effort it takes to plan for, develop, and implement computer- ized systems and services, it's not terribly surprising that we've overlooked one element in our technological program, but it is key: publicity. We must get the word out to our primary clientele that we can do for them what they've been going to others for. Just as we were responsible for making the system or the service available, so too are we responsible for letting users know it's ready to be used.

Our library has a committee, the Library Instructional Services Committee (LISC), whose main purpose is to plan, develop, and coordinate instructional activities throughout the library. With our recent rapid technological advancements, this committee focused on developing strategies for publicizing our online and ondisk services across campus, and for instructing patrons in the use of those systems.

We have tried several advertising and instructional techniques: seminars for "faculty only," drop-in online instructional,sessions, research consultations, newsletters, and more. These were partly successful-we got a small response-but none of them brought people into the library in the large numbers we need to reach. We have a potential primary-use clientele of over 20,000 , and those programs were reaching only 20 or so people at a time.

So when we heard that the university was sponsoring a campus media fair for computer projects, several of us took part in it. We had no portable systems we could transport to the fair, but we reserved an exhibit booth and took boxes full of printed literature and guides describing our computerized services and programs to distribute.

\section{Going to the fair}

In that one day by participating in this fair we reached more graduate students and faculty 

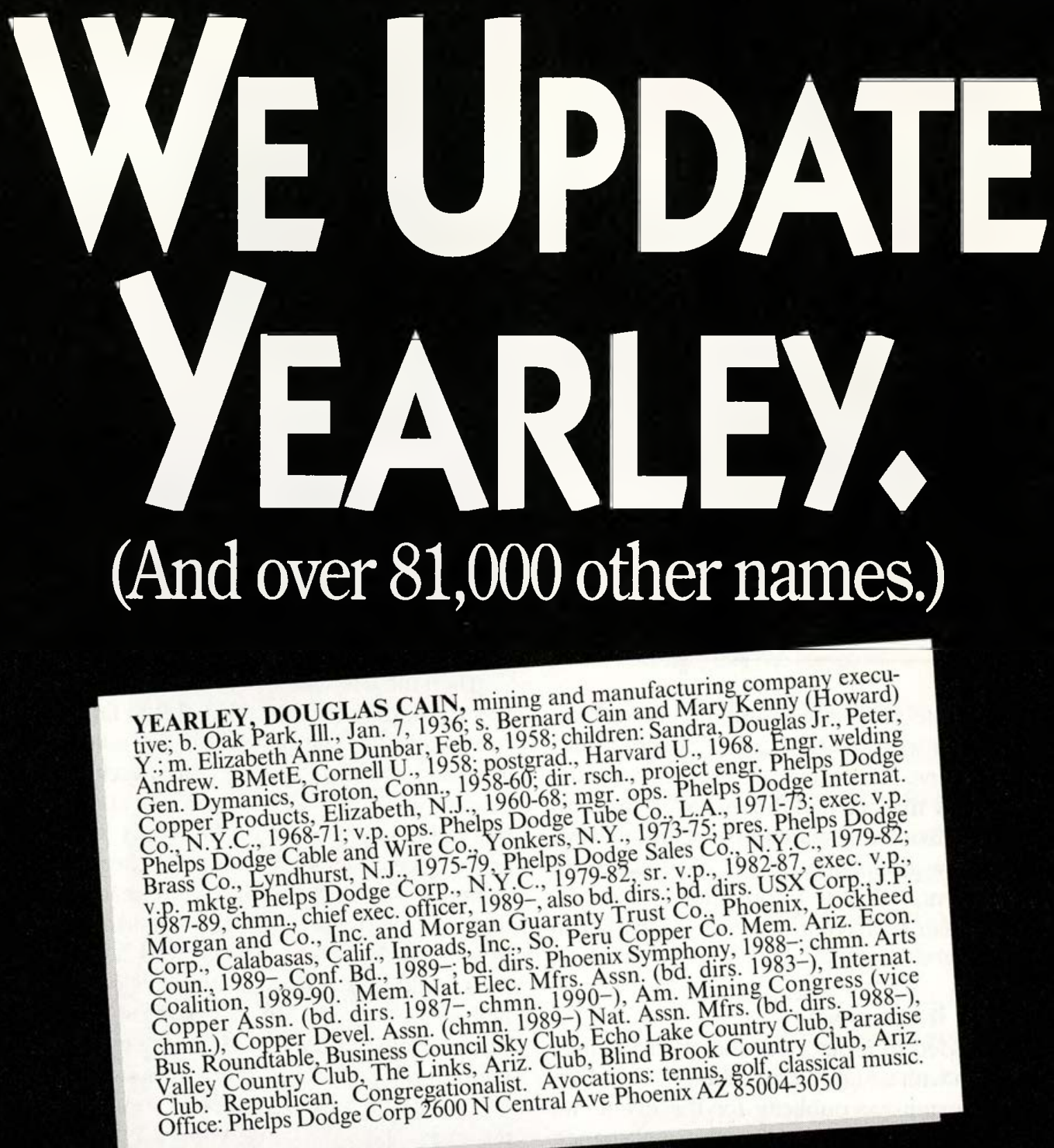

A lot can change in a year-especially when it don't stop there. Researchers will now be able comes to people in the public spotlight. That's to take advantage of our latest innovationwhy, starting with the new 1994 edition of the Geographic/Professional Index now

Marquis Who's Who in America, we will be publishing yearly.

This year alone there are over 13,000 new entries and 55,000 updated biographies. And the changes

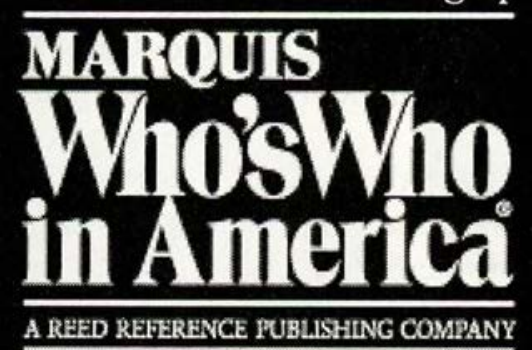

included at no extra charge.

It's no wonder, that since 1899 , more researchers turn to Who's Who in America as America's foremost biographical reference.

\section{To order your 1994 edition, call 800-521-8110 today.}


than we had in any five of our other special library sessions. The very nature of the fair invited mass participation: it was set up in the University Center (a focal point on campus), it was arranged so people could wander in and out at will-strolling past exhibits but not necessarily devoting their attention to any one item-and it offered a variety of individuals demonstrating their special interests: projects they had been working on daily for months or years, about which they were enormously enthusiastic. Watching the excitement generated by this fair, it occurred to us we could adapt the concept for our purposes.

\section{We wanted to show off the}

library with an eye toward its

most favorable, forwardthinking functions.

We wanted to show off the library with an eye toward its most favorable, forward-thinking functions. We wanted to let our potential users know that we had the means to respond to their individual research needs, and that we could show them how to get easy access to very current, valuable information. What better way than by having our own media fair in the library?

\section{Making it our own}

LISC decided to replace several other planned programs with a high-profile Library Media Fair. We did extensive publicity for the event: we placed color ads in the campus newspaper, plastered bulletin boards with bright, inviting posters, got some public-service announcements on the campus radio station, and handdistributed a snazzy flyer describing the event to all faculty and graduate student mailboxes. We called faculty colleagues (at UCSB, every public service librarian is also a manager of one or more library collections) and urged them to get the word out, too.

LISC committee members assembled the fair in our largest, most accessible library meeting room, and staffed the various computer workstations and booths. We had plenty of technology to showcase. In addition to our new online public access catalog, we made over 50 CD-ROM databases available. The University of California systemwide online catalog, MELVYL, also runs many journal and newspaper index databases. We had plenty of free passwords ready to issue to faculty and students for searching these databases remotely, as well as step-by-step instructions for calling in, making connections, and searching.

We were ready to show interested travellers maps and pathways through the Internet. We had six workstations in place to access the CDs, OPAC, and MELVYL. We'd done all the advance work, next we waited to see the results.

\section{Opening day}

The first to arrive were other librarians who wanted to see what we'd done and offer moral support. Next members of the library administration wandered in - the pressure was on us for a high-volume turnout. They took up strategic positions for counting heads. If the fair did not pull in the numbers, we wouldn't be repeating it.

Then the clients starting coming in. By ones and twos, they strolled through the fair, going from station to station picking up guides and information sheets, stopping to watch a demonstration or talk with a searcher about their particular interests. More librarians appeared and we pressed them into service: users wanted in-depth consultations, they were ready to talk with a subject specialist, they had to get that free MELVYL password now, and how was it they could search Dartmouth's catalog? At several points, we had to take names and numbers for follow-up contacts-there just weren't enough of us to cover everyone's questions.

One of the most oft-repeated comments that day was: "I didn't know you had this," or its variation, "I didn't know the library could do this for me." Our keenly satisfying reply was, of course, "Let me show you this, too!"

\section{The sweet signs of success}

When the fair was over, we easily counted it a success. From talking with participants we knew we'd brought in people who had never used these services before. We also made crucial connections with faculty department heads and graduate students just starting their research. We'd distributed stacks of printed material to individuals willing to take them back to their departments and pass them around. We effectively illustrated that the library was very much

(continued on page 511) 


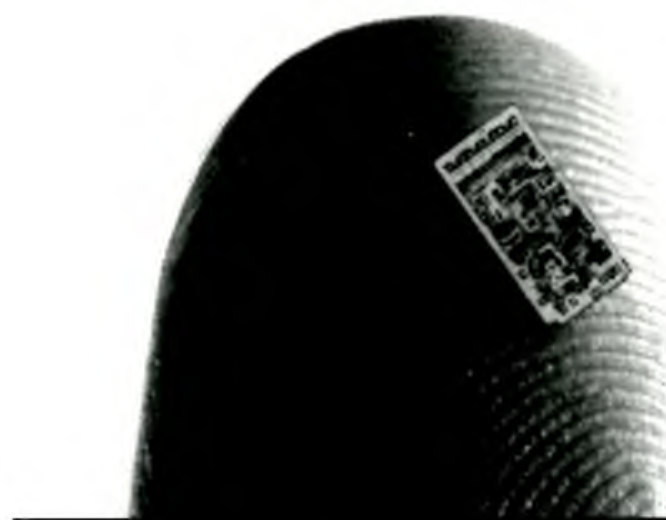

It's called a semiconductor chip mask work the unique design, or fingerprint, of a computer chip. For U.S. high-tech firms, the creation of new, more advanced chip designs involves a huge investment. But for producers in some nations, computer chips are fair game - easily copied and enormously profitable.

The protection of Intellectual Property -

\section{YEARS IN RESEARCH, MILLIONS IN DEVELOPMENT} AND RIPPED OFF OVERNIGHT.

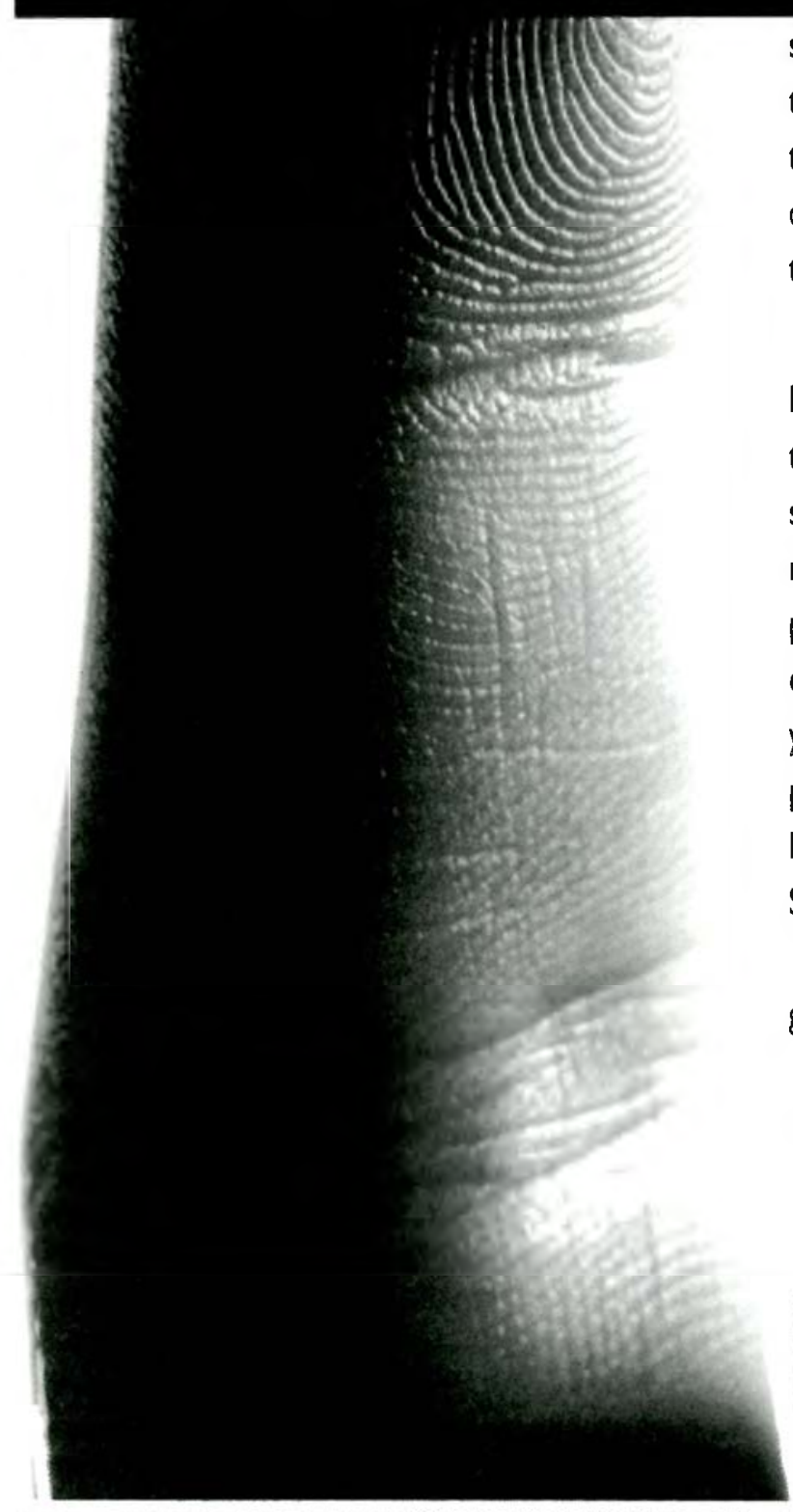

such as chip mask works, patents and trademarks - is one of the most hotly debated topics worldwide. And it's just one of thousands of important topics you can explore quickly and thoroughly using PAIS International.

\section{Gain a global perspective}

PAIS provides easy access to over 350,000 hardto-find journal articles, government documents, statistical directories, monographs, conference reports and more from all over the world. From public policy to international law, from trade to demographics, PAIS connects you to information you won't find anywhere else. Plus, PAIS provides a global perspective via references to literature published in French, German, Italian, Spanish and Portuguese, as well as English.

Next time you have a tough question, don't get ripped-off. Get connected with PAIS.

Public Affoirs Information Service ${ }^{\circledast}$, inc 521 West 43rd Street, New York, NY 10036-4396 800-288-PAIS, $212-736.6629$ (in NYC) Fox: 212-643-2848

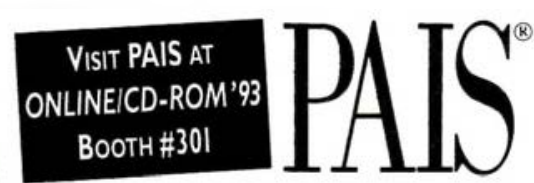

No one looks at the world like PAIS

In Print: PAIS INTERNATIONAL IN PRINT ${ }^{\circ}$ PAIS SUBIECT HEADINGS Online Through: BRS • DATA-STAR • DIALOG • OCLC • RLG On CD.ROM: PAIS ON CD-ROM • PAIS INTERNATIONAL ON SILVER PLATTER On Magnetic Tape: CONTACT PAIS FOR INFORMATION 


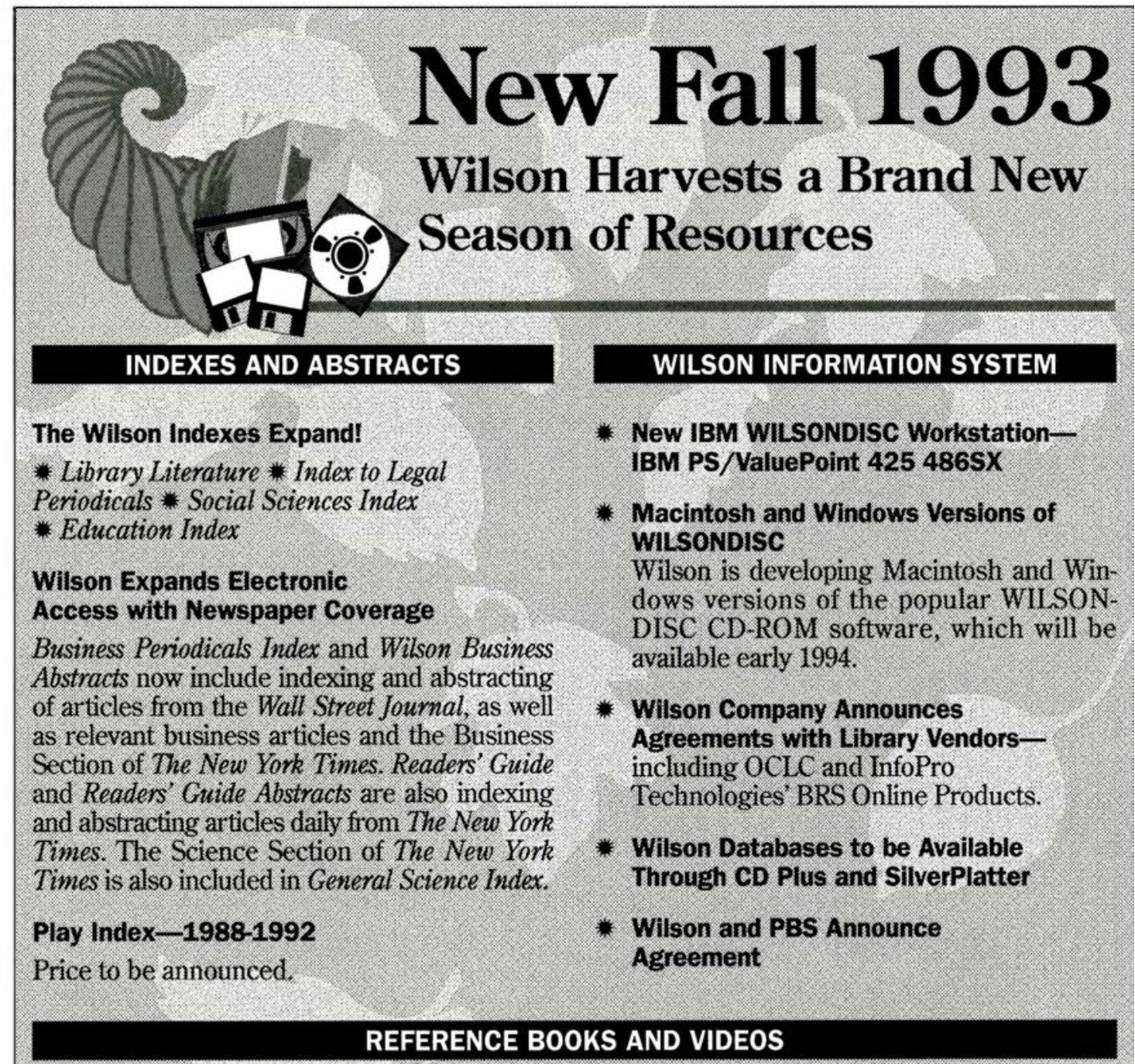

\section{Old Worlds to New}

The Age of Exploration and Discovery By Janet Podell and Steven Anzovin 296pp. 1993 ISBN 0-8242-0838-2 $\$ 44$ U.S. and Canada, \$49 other countries.

Facts About the Presidents, Sixth Edition

By Joseph Nathan Kane

432pp. 1993 ISBN 0-8242-0845-5

$\$ 55$ U.S. and Canada, $\$ 60$ other countries.

\section{Booktalk! 5}

Edited by Joni Richards Bodart

300 pp. approx. Fall 1993

ISBN 0-8242-0836-6

$\$ 32$ U.S. and Canada, \$36 other countries.

\section{Stories on Stage}

Scripts for Reader's Theater

By Aaron Shepard

162pp. 1993

ISBN 0-8242-0851-X

$\$ 40$ U.S. and Canada, $\$ 45$ other countries.

How to Use the Readers' Guide Videocassette. 20 minutes 1993

Color/VHS/Hi-Fi

ISBN 0-8242-0846-3

$\$ 49$ U.S. and Canada, $\$ 59$ other countries.

For More Information or To Order Call Toll-Free 800-367-6770.

Outside of the U.S. and Canada call 718-588-8400. Fax 718-590-1617. 
- Psyc@PUCC (Psycoloquy; all areas of Psychology)

- Psygrd-J@UOTTAWA (Psycgrad; Psychology Graduate Student Articles)

- Psyche-L@NKI (Psyche; Consciousness)

- To browse archives of Internet serials, Gopher to GOPHER CIC.NET 70; choose Electronic Serials, and then the alphabetical listing, and under " $p$ " you can browse or retrieve issues of Psycoloquy or Psycgrad from this site.

\section{Electronic conferences (Listserv lists)}

Conferences listed below are a sampling of the over 20 in psychology which are currently active. To subscribe to the electronic conferences listed below, follow the sample shown above for subscribing to electronic journals.

- AUTISM@SJUVM (Developmental Disabilities)

- BEHAVIOR@ASUACAD (Behavior Disorders in Children/Youth)

- ADDICT-L@KENTVM (Addictions other than Alcohol/Drugs)

- MPSYCH-L@BROWNVM (Mathematical Psychology)

- DIV28@GWUVM (APA's Div 28; Psychopharmacology)

\section{Grants and funding in psychology}

- Abstracts of NSF Grant Awards in psychology (from 1990): Gopher to STIS.NSF.GOV 70; do a keyword search on psychology after choosing the Index to NSF Award Abstracts.

- Announcements of Grants/Funding in psychology: Subscribe to APASD-L; subscription address is LISTSERV@VTVM2.

- Also: Telnet to INFO.ACS.UNC.EDU (login INFO), choose Research, and then search keyword "psychology" in Grants and Funding Index.

\section{Software and computer use for psychology research}

The first two of these items have browseable/ retrievable archives; and MacPsych is keyword searchable as well.

- Reviews of Psychology Software: Gopher to BARYON.HAWK.PLATTSBURGH.EDU 70; choose SUNY Plattsburgh Information and then COMPSYCH.

- Psychology Research with the Macintosh: Gopher to GOPHER.STOLAF.EDU 70; under Network Resources, then St. Olaf Mailing Lists.

- Discussion of Experiment Generator Packages: Subscribe to PSYCH-EXPTS; send e-mail to MAILBASE@MAILBASE.AC.UK; message = join psych-expts yourFirstname yourLastname

\section{Datafiles}

- For ICPSR Datafiles/Information: Gopher to DATALIB.LIBRARY.UALBERTA.CA 70.

- For Social Science Data/Archive Information: Telnet to HAR1.HUJI.AC.IL, login as SSDA, choose Online Aleph and then Social Science Data Archive; for Institute for Research in Social Sciences Information: Telnet to info.acs.unc .edu, login as INFO; look in Research selection.

- For electronic conference discussion of social science data: Subscribe to SOS-DATA using steps listed above with e-mail to LISTSERV (a)UNCVM1.

- For Psycoloquy Article (with responses) proposing archiving and access on the Internet of data gathered in psychology research: Gopher to GOPHER.CIC.NET 70; find Psycoloquy under $\mathrm{P}$ in alphabetical list under Electronic Serials, and find items PSYC.92.3.29, PSYC.92.3.55, PSYC.92.3.56, PSYC.92.3.57, the articles by Skoyles, Graham, Gelobter and Jennings).

(Marketing the library con't from page 504)

a part of the computerized education process.

We will hold another Library Media Fair as soon as we can allocate enough librarian time to organize and staff it. The only trouble is, just as we've been flooded with users anxious to learn how to dial in and search, we've had massive retirements and a freeze has been placed on vacant positions. The squeeze between increased user needs and decreased personnel is on.

\section{What next?}

So our next step will be to maximize librarian time and effort-we're concentrating on our publications' program and investing in more sophisticated desktop publishing equipment. Our reasoning is that if we take the time to produce an eye-catching guide once, it will be used hundreds of times (and will be available even when a librarian isn't).

That single media fair made so many users aware of our services that we're still following up with passwords and answering incoming phone calls nearly a year later. As a means of marketing the library in its most positive light, we highly recommend the fair format. 